This is the peer reviewed version of the following article: "Abbasi. H., Antunes, M., Velasco, J.I. (2018). Enhancing the electrical conductivity of polyetherimidebased foams by simultaneously increasing the porosity and graphene nanoplatelets dispersion. Polymer composites, vol. 40, S2 Special Issue: Graphene and Carbon Fibers, p. E1416-E1425" which has been published in final form at [doi: 10.1002/pc.25029]. This article may be used for non-commercial purposes in accordance with Wiley Terms and Conditions for Self-Archiving." 


\title{
Enhancing the electrical conductivity of polyetherimide-based foams by simultaneously increasing the porosity and graphene nanoplatelets dispersion
}

\author{
H. Abbasi, M. Antunes, J.I. Velasco* \\ Centre Català del Plàstic. Universitat Politècnica de Catalunya (UPC • BarcelonaTech), \\ Departament de Ciència dels Materials i Enginyeria Metal·lúrgica. C/Colom 114, E-08222, \\ Terrassa, Barcelona, Spain \\ Tel.: (+34)937837022; Fax: (+34)937841827 \\ *Corresponding author: J.I. Velasco (jose.ignacio.velasco@upc.edu)
}


Title of the manuscript: Enhancing the electrical conductivity of polyetherimide-based foams by simultaneously increasing the porosity and graphene nanoplatelets dispersion

Authors: H. Abbasi, M. Antunes, J.I. Velasco*

Affiliation and address: Centre Català del Plàstic. Universitat Politècnica de Catalunya (UPC · BarcelonaTech), Departament de Ciència dels Materials i Enginyeria Metal·lúrgica. C/Colom 114, E-08222, Terrassa, Barcelona, Spain

Tel.: (+34)937837022; Fax: (+34)937841827

* Corresponding author: J.I. Velasco (jose.ignacio.velasco@upc.edu)

\begin{abstract}
Significant improvement in electrical conductivity of graphene nanoplatelets-filled polyetherimide (PEI) foams was achieved by simultaneously increasing the porosity and graphene nanoplatelets dispersion. Foams were prepared by means of water vapor-induced phase separation using a concentration of graphene nanoplatelets $(\mathrm{GnP})$ between 1 and 10 $w t \%$. In order to obtain two sets of foams having different density and porosity, PEI's concentration in N-methyl pyrrolidone (NMP) solvent prior to foaming was set at 15 and 25$30 \mathrm{wt} \%$, respectively. High power sonication was applied to GnP-NMP suspension before PEI's addition for the foam series with higher porosity (15 wt\% PEI). All foams were later characterized in terms of cellular structure, thermal stability, dynamic-mechanical properties and electrical conductivity. A notable enhancement in electrical conductivity was observed with foaming, especially when increasing the porosity and applying sonication, with foams reaching values as high as $1.7 \times 10^{-1} \mathrm{~S} / \mathrm{m}$ while maintaining the thermal stability and mechanical performance.
\end{abstract}




\section{Introduction}

Polyetherimide (PEI) is one of the most used high performance thermoplastic polymers in advanced applications due to its outstanding combination of high mechanical performance, flame and chemical resistances, as well as thermal and dimensional stabilities. The preparation of PEI-based foams reinforced with carbon-based nanoparticles using water vapor induced phase separation (WVIPS) has shown promising results in terms of homogeneity and filler dispersion [1-4]. Other foaming methods such as solid state and microcellular injection molding have also been used to investigate the effects of fillers such as multi-wall carbon nanotubes (MWCNT), montmorillonite (MMT) or talc [5].

Liquid-phase exfoliation has raised a lot of attention in past years due to its potential industrial scalability [6]. The exfoliation of graphene nanoplatelets stacks in liquid environments can be realized by the application of ultrasounds and graphene layer stabilization using organic solvents [5]. Solvent selection is highly dependent on the interfacial tension between solid and liquid. A high interfacial tension results in poor dispersion of the solid in the liquid due to the high energy value of work of cohesion and restacking [7]. Consequently, solvents with a surface tension close to $40 \mathrm{~mJ} \cdot \mathrm{m}^{-2}$, e.g. N-methyl pyrrolidone (NMP) with $40 \mathrm{~mJ} \cdot \mathrm{m}^{-2}$ and N,N-dimethylformamide (DMF) with $37.1 \mathrm{~mJ} \cdot \mathrm{m}^{-2}$, have proven suitable for graphene dispersion due to the reduction of the interfacial tension between solvent and graphene [6]. Additionally, NMP has shown a promising level of solubility for a vast range of high performance polymers, such as PEI. In the case of the WVIPS foaming method, although providing a high level of homogeneity, the kinetic of the process is not capable of providing the required conditions to properly separate the graphene layers. A possibility to counteract this limitation and provide the required energy for breaking the van der Waals forces keeping together the graphene layers could be the application of ultrasonication to the GnP-solvent suspension prior to foaming [8-10].

Proper dispersion of conductive nanofillers is known to be crucial in optimizing the transport properties of polymer nanocomposites. In a previous work, we reported that graphene-filled PEI foams prepared by WVIPS presented promising electrical conductivity values while enhancing the mechanical and thermal properties of the base material [1]. Another research conducted by Ling et al. [2] showed that foaming led to improvements in the electrical conductivity of PEI-graphene nanocomposite foams prepared by a similar procedure. Their measurements revealed that while the addition of $10 \mathrm{wt} \%$ graphene already led to significant enhancements in electrical conductivity, PEI-graphene nanocomposites reaching electrical 
conductivities as high as $4.8 \times 10^{-4} \mathrm{~S} / \mathrm{m}$, it was after foaming that PEI-graphene nanocomposites displayed the highest value, further increasing the electrical conductivity in almost one order of magnitude $\left(2.2 \times 10^{-3} \mathrm{~S} / \mathrm{m}\right)$, demonstrating the influence of foaming in terms of enhancing electrical conductivity.

Although various studies based on PEI reinforced with graphene have been carried out $[1,2$, $6,11,12$ ], highly conductive PEI-GnP foams with thicknesses above $1 \mathrm{~mm}$ have not been explored. This article considers investigating the effects of prior sonication of GnP in NMP dissolution and significant density reduction through foaming on the electrical properties of PEI foams containing variable concentrations of graphene (1-10 wt\%), with the final goal of developing lightweight materials for advanced applications such as fuel cells or EMI shielding. General characterization of the cellular structure and morphology of foams, thermal stability and dynamic-mechanical properties have been carried out and compared with foams prepared without high power sonication. Finally, the electrical conductivity measurements were performed to study the effectiveness of sonication and density reduction on favouring the formation of a GnP conductive network in the foams.

\section{Experimental}

\subsection{Materials}

Thermoplastic polyetherimide (PEI), with the commercial name of Ultem 1000, manufactured by Sabic, was used. PEI Ultem 1000 has a density of $1.27 \mathrm{~g} / \mathrm{cm}^{3}$ and a glass transition temperature $\left(T_{\mathrm{g}}\right)$ of $217^{\circ} \mathrm{C}$.

Graphene nanoplatelets, for now on known as GnP (commercial name xGnPM-15 and density of $2.2 \mathrm{~g} / \mathrm{cm}^{3}$ ), were supplied by XG Sciences. These nanofillers are formed by stacks of graphene nanoplatelets having an average thickness of 6-8 $\mathrm{nm}$ and a lateral size of $15 \mu \mathrm{m}$, with a surface area of $120-150 \mathrm{~m}^{2} / \mathrm{g}$ and an electrical conductivity of $10^{7}$ and $10^{2} \mathrm{~S} / \mathrm{m}$, respectively measured parallel and perpendicular to their surface, as reported by the manufacturer.

N-methyl pyrrolidone (NMP), with a purity of $99 \%$, a boiling point of $202{ }^{\circ} \mathrm{C}$ and a flash point of $95^{\circ} \mathrm{C}$, was acquired from Panreac Co.

\subsection{Foam preparation}

The preparation of PEI-GnP foams was carried out using water vapor induced phase separation (WVIPS). A first series of foams, for now on known as Series 1, was prepared with 
a high concentration of PEI (25-30 wt $\%$ ) in NMP, using 1, 2, 5 and $10 \mathrm{wt} \%$ of GnP. A second series of foams (Series 2) was prepared with the objective of improving GnP's dispersion in PEI by combining the application of high power sonication and porosity increase by means of reducing PEI's concentration in NMP (15 wt\%). Details are given as follows:

The foaming procedure begins with the dispersion of $3 \mathrm{~g}$ of GnP into $146 \mathrm{ml}$ of NMP, which is known to be a practical solvent for graphene suspension at room temperature [13]. High power probe sonication was applied for 30 minutes using a Fisher Scientific FB-705 ultrasonic processor with a $12 \mathrm{~mm}$ solid tip probe at $100 \%$ amplitude and $20 \mathrm{kHz}$ output, applying a total amount of energy of $190 \mathrm{~kJ}$ at $95-130 \mathrm{~W}$, while placing the suspension in an ice-bath to maintain a constant temperature of $50{ }^{\circ} \mathrm{C}$. In the following step, PEI was dissolved in the suspension containing the sonicated GnP (27 g of PEI in $153 \mathrm{~g}$ of NMP-GnP solution, i.e., a $15 \mathrm{wt} \%$ PEI solution) at $75^{\circ} \mathrm{C}$ and kept stirring at $450 \mathrm{rpm}$ for 24 hours. Afterwards, the GnP-rich solution was diluted with PEI-NMP (also $15 \mathrm{wt} \%$ PEI in NMP) to obtain the 1, 2, 5 and $10 \mathrm{wt} \% \mathrm{GnP}$-filled nanocomposites. Subsequently, each solution was poured on a flat glass exposed to air with an average measured humidity of $75 \%$ at room temperature for 4 days, which promoted foaming of the polymer by means of WVIPS. The resulting foams were then washed with a 50/50 mixture of ethanol and water followed by extraction of the remaining solvent, utilizing stirring in hot water at $90{ }^{\circ} \mathrm{C}$ for 7 days and intensively drying under vacuum at $140{ }^{\circ} \mathrm{C}$ for 7 additional days to fully extract the residual NMP. Typical density of the prepared foams was approximately $0.3 \mathrm{~g} / \mathrm{cm}^{3}$ with a final thickness of around 5 $\mathrm{mm}$. Samples were later cut directly from the prepared foams and used in the several characterizations.

\subsection{Testing procedure}

The density of the foams was measured according to a standard procedure (ISO 845). Due to the particular foam preparation procedure it was not possible to directly obtain the unfoamed nanocomposites and, therefore, their density could only be theoretically calculated using the rule of mixtures from the density values of PEI, GnP and their respective calculated volume fractions. The morphology of the studied foams was analyzed using a JEOL JSM-5610 scanning electron microscope. Samples were prepared by brittle fracturing the foams using liquid nitrogen and sputter depositing a thin layer of gold onto the fractured surface with a BAL-TEC SCD005 Sputter Coater. The values of the average cell size $(\Phi)$, cell nucleation density and cell density ( $N_{0}$ and $N_{\mathrm{f}}$, respectively) were determined from the analysis of SEM 
micrographs using the intercept counting method [14]. Particularly, $N_{0}$ and $N_{\mathrm{f}}$ were calculated assuming an isotropic distribution of spherical cells according to equations (1) and (2):

$$
\begin{aligned}
& N_{0}=\left(\frac{n}{A}\right)^{3 / 2}\left(\frac{\rho_{s}}{\rho}\right) \\
& N_{f}=\frac{6}{\pi \Phi^{3}}\left(1-\frac{\rho}{\rho_{s}}\right)
\end{aligned}
$$

Where $n$ is the number of cells in the micrograph, $A\left(\mathrm{~cm}^{2}\right)$ is its area and $\rho_{\mathrm{s}}$ and $\rho$ the solid and foam densities, respectively. In equations (1) and (2), $N_{0}$ represents the number of cells per volume of unfoamed material and $N_{\mathrm{f}}$ the number of cells per volume of foamed material.

The analysis of the crystalline characteristics of PEI-GnP foams was carried out by means of wide-angle X-ray diffraction (XRD) using a Panalytical diffractometer operating with $\mathrm{CuK} \alpha$ $(\lambda=0.154 \mathrm{~nm})$ at $40 \mathrm{kV}$ and $40 \mathrm{~mA}$. Scans were taken from $2^{\circ}$ to $60^{\circ}$ using a scan step of $0.033^{\circ}$.

A TGA/DSC 1 Mettler Toledo STAR System analyzer was used to evaluate the thermal stability of foams by performing thermogravimetric analysis by heating samples of around 8.0 mg from 30 to $1000{ }^{\circ} \mathrm{C}$ at $10{ }^{\circ} \mathrm{C} / \mathrm{min}$ under a nitrogen atmosphere (constant flow of 30 $\mathrm{ml} / \mathrm{min}$ ). Three different samples were measured for each material.

Dynamic-mechanical analysis was used to analyze the storage and loss moduli of the foams, as well as PEI's glass transition temperature $\left(T_{\mathrm{g}}\right)$. A DMA Q800 from TA Instruments was used and calibrated in a single cantilever configuration. The experiments were performed from 30 to $300{ }^{\circ} \mathrm{C}$ at a heating rate of $2{ }^{\circ} \mathrm{C} / \mathrm{min}$ and frequency of $1 \mathrm{~Hz}$ applying a dynamic strain of $0.02 \%$. Test specimens were prepared in a rectangular shape with a typical length of $35.5 \pm 1.0 \mathrm{~mm}$, width of $12.5 \pm 1.0 \mathrm{~mm}$ and thickness of $3.0 \pm 0.5 \mathrm{~mm}$. Three different measurements were performed for each material (error $<5 \%$ ).

Samples of $20 \mathrm{~mm} \times 20 \mathrm{~mm} \times 1 \mathrm{~mm}$ were prepared to measure the electrical conductivity using a 4140B model HP pA meter/dc voltage source with a two-probe set. The surfaces of the samples in contact with the copper electrode pads were covered with a thin layer of colloidal silver conductive paint having an electrical resistance between 0.01 and $0.1 \Omega / \mathrm{cm}^{2}$ in order to guarantee a perfect electrical contact. A programmable direct current voltage feature with a range of $0-20 \mathrm{~V}$ with a voltage step of $0.05 \mathrm{~V}$, a hold time of 10 seconds and a step delay time of 5 seconds, was applied. 


\section{Results and discussion}

\subsection{Cellular structure and morphology}

The cellular structure characterization results of PEI-GnP nanocomposite foams are presented in Table 1, and typical SEM micrographs are shown in Figure 1. All foams presented a homogenous cellular structure. Due to the high concentration of PEI (25-30 wt\%), Series 1 foams displayed high densities $\left(0.47-0.59 \mathrm{~g} / \mathrm{cm}^{3}\right)$, corresponding to a porosity interval from 54 to $64 \%$. As a consequence of the high viscosity of the solution, the resultant foams displayed small cells (11-13 $\mu \mathrm{m}$ in size) and high cell densities around $10^{9}$ cells $/ \mathrm{cm}^{3}$. No clear trends were observed in cell size and cell density with increasing GnP concentration, as cellular morphology seemed to be controlled by the high viscosity of the solution resulting from the high concentration of PEI.

As expected from the lower concentration of PEI (15 wt\%), Series 2 foams showed lower densities and hence increased porosities when compared to foams from Series 1, particularly around a $40 \%$ density reduction and $25 \%$ porosity increase. In fact, the relative reduction of the amount of PEI in both series is also around 40\%. Direct consequence of the lower viscosity of PEI-based solution resulting from lower polymer concentration, Series 2 foams displayed bigger cells $\left(23-37 \mu \mathrm{m}\right.$ in size) and lower cell densities $\left(10^{7}-10^{8}\right.$ cells $\left./ \mathrm{cm}^{3}\right)$. In this Series the amount of GnP seemed to have a bigger influence in foam's morphology. Particularly, as the concentration of sonicated GnP increased, the average cell size decreased and cell density increased. High power sonication promoted GnP's dispersion and, therefore, a more viscous solution, limiting cell growth. Said result could be the combination of a better dispersion of $\mathrm{GnP}$ in the solution and a reduction of GnP's actual size in the form of few-layer nanoplatelets due to the application of high power sonication, which, consequently, induces an increase in GnP's surface area. Consequently, the cellular morphology of these foams could be controlled by the amounts of both PEI and sonicated GnP.

As can be seen in the micrographs presented in Figure 2, the stacks of GnP, whose original lateral size was $15 \mu \mathrm{m}$, resulted better dispersed and with a reduction in size (around 1-5 $\mu \mathrm{m}$ ) in Series 2 foams (Figure 2(b)) when compared to Series 1 (Figure 2 (a)), which seemed to ultimately lead to a more homogenous cellular structure after foaming.

The analysis of the XRD spectra could clarify differences in GnP dispersion and possible exfoliation due to polymer concentration and specially the application of sonication during foaming. As can be seen in Figure 3 all foams presented a strong sharp diffraction peak at $2 \theta$ $=26.5^{\circ}$ corresponding to the (002) diffraction plane of GnP. Comparatively, for equal GnP 
concentrations, PEI-GnP foams from Series 2 presented a reduction of the normalized intensity of this peak when compared to foams from Series 1 (see values presented in Table 2), which was related to an enhanced dispersion and certain level of $\mathrm{GnP}$ exfoliation, reaffirming prior SEM conclusions. The increase in the full width at half maximum (FWHM) of this peak in PEI-GnP foams from Series 2 when compared to the ones from Series 1 seems to further support the conclusion of an improvement in $\mathrm{GnP}$ dispersion due to the application of high power sonication.

\subsection{Thermal stability}

Thermogravimetric analysis results are presented in Table 3 and in Figures 4 and 5. Figure 4 shows the thermogravimetric weight loss and respective first derivative (dTG) thermograms of pure PEI foam and Series 2 foams. PEI-GnP foams presented a characteristic two-step thermal decomposition similar to pure PEI foam at around $530{ }^{\circ} \mathrm{C}$ and $580{ }^{\circ} \mathrm{C}$, respectively related to the rupture of the aliphatic part of PEI followed by a second stage of decomposition of the aromatic part [1]. The residual weight remained above $50 \mathrm{wt} \%$ at $1000{ }^{\circ} \mathrm{C}$ for all foams. In both series of foams the onset temperature of decomposition was approximately between $502{ }^{\circ} \mathrm{C}$ and $515{ }^{\circ} \mathrm{C}$, without any significant variation between them or a clear tendency in any of the series, though a slight increase could be observed with increasing GnP's concentration. Therefore, the resulting porosity, cellular morphology and application of high power sonication did not seem to influence the thermal stability at the beginning of the decomposition. A similar trend was observed with respect to the temperature corresponding to the maximum velocity of the decomposition $\left(T_{\max }\right)$, which took place within the range of 520 ${ }^{\circ} \mathrm{C}$ to $535{ }^{\circ} \mathrm{C}$ in the case of Series 1 and between $523{ }^{\circ} \mathrm{C}$ and $532{ }^{\circ} \mathrm{C}$ in Series 2 .

Differences in thermal stability of the foams appeared at the advanced stages of decomposition. A general increasing trend of temperature was observed at $40 \mathrm{wt} \%$ loss with increasing GnP's content in both series of foams. Particularly, with rising the amount of GnP from 5 to $10 \mathrm{wt} \%, T_{40 \%}$ increased by around $54{ }^{\circ} \mathrm{C}$ and $30{ }^{\circ} \mathrm{C}$ in Series 1 and Series 2, respectively. Two competitive effects corresponding to the presence of $\mathrm{GnP}$ nanoparticles seemed to influence the thermal decomposition of the foams. On the one hand, the typical layered structure of the particles incorporates tortuosity in the continuous phase, incrementing the barrier effect against the diffusion of combustible gases produced during the pyrolysis, and the heat transfer [15]. Given the fact that sonication reduces individual GnP's area, the barrier effect should lose its influence in Series 2 foams, explaining their lower thermal 
stability. On the other hand, due to high thermal conductivity of GnP, their higher concentration in the foams should accelerate the heat transfer velocity in the continuous phase, reducing thermal stability, therefore competing with the previously mentioned barrier effect. While reducing GnP's area, sonication could also contribute in an indirect way to increase the thermal conductivity of the material, resulting in decompositions at lower temperatures.

\subsection{Dynamic-mechanical properties}

In a general view, changes in both elastic and viscous response of the foams in Series 1 and 2 were observed (see Figure 6). Series 1 foams presented a better elastic behaviour when compared to foams from Series 2, while the viscous response had a contrary trend, showing a better filler-matrix interaction in Series 2.

Significant differences in elastic behaviour were observed between both series of foams. Comparatively, Series 1 foams presented significantly higher storage modulus values than foams from Series 2. Various causes could explain these differences: First of all, the higher density of Series 1 foams and, secondly, their finer cellular morphology and globally larger $\mathrm{GnP}$ area size. Hence, as shown in Figure 6 (b), the normalized storage modulus $\left(E{ }^{\prime}{ }_{\text {norm }}=\right.$ $E^{\prime} / E_{\mathrm{s}}$ ) presents a general increasing tendency with increasing relative density, with Series 1 foams presenting higher values than those from Series 2. Additionally, as presented in Figure 6 (c), the specific storage modulus grows with increasing the amount of GnP. The effect of GnP's concentration is greater in Series 1 foams, showing a sharper tendency when compared to foams from Series 2. These differences could be explained based on either the greater reinforcement effect of non-sonicated $\mathrm{GnP}$, consequence of its bigger area size, or the smaller average cell size of Series 1 foams, or a combination of both.

Regarding the viscous response, the maximum temperature of loss modulus and $\tan \delta$ resulted in slightly higher values for foams from Series 2 , reaching $8{ }^{\circ} \mathrm{C}$ of difference for foams containing $10 \mathrm{wt} \% \mathrm{GnP}$. Considering that the maximum temperatures of $E$ ', and tan $\delta$ reflect the glass transition temperature of the polymer, the appearance of measured differences indicates a greater interaction between the sonicated particles and the polymer and, as a consequence, a greater restriction to molecular mobility in Series 2 foams. Moreover, no clear tendency was observed with GnP's content. Said result could be explained by the previously 
mentioned enhanced dispersion and reduction in stack size of GnP due to sonication, which increases the surface area of GnPs and hence their surface interaction with PEI's molecules. The values of foam's glass transition temperature $\left(T_{\mathrm{g}}\right)$, obtained from the maximum of the transition peak in both loss modulus $\left(E^{\prime \prime}\right)$ and $\tan \delta$ curves, the storage modulus $\left(E^{\prime}\right)$ and its specific value $\left(E_{\mathrm{sp}}\right)$, i.e. the storage modulus divided by the density of the sample, were extracted from the dynamic-mechanical analysis curves of Series 1 and Series 2 foams and are presented in Table 4. Typical $E^{\prime}, E^{\prime}$, and $\tan \delta$ curves of PEI-GnP foams are presented in Figure $6(\mathrm{a})$.

As it is known, density plays a vital role on the storage modulus of foams. The reduction in density shows a greater impact on its absolute value when compared to the effect of GnP sonication, for instance the $5 \mathrm{wt} \% \mathrm{GnP}$ foam presenting a lower absolute value of the storage modulus than the sample with $1 \mathrm{wt} \% \mathrm{GnP}$. In terms of mechanical models developed for foams, Gibson and Ashby [16] developed a model that considered foams as a cubic array of individual units:

$\frac{E}{E_{s}} \approx C\left(\frac{\rho}{\rho_{s}}\right)^{n}$

With $\rho$ and $E$ being the density and the elastic modulus of the foam and $\rho_{\mathrm{s}}$ and $E_{S}$ those of the respective unfoamed counterpart. In this model $C$ represents the geometry constants of proportionality and is commonly assumed to be equal to 1 .

So, by representing the normalized storage modulus, $E^{\prime}{ }_{\text {norm }}\left(E^{\prime}{ }_{\text {norm }}=E^{\prime} / E^{\prime}{ }_{\mathrm{s}}\right)$ at $30^{\circ} \mathrm{C}$ as a function of relative density, as presented in Figure 6 (b), it is possible to determine the value of exponent $n$, which has been related to the efficiency of foaming, with values close to 1 indicating a more smooth decrease in modulus with foaming, characteristic of closed-cell structures with homogeneous and small cell sizes, and values close to 2 , having a more abrupt reduction, characteristic of open-cell foams. A value of $n=1.35$ was obtained considering all PEI-GnP foams, indicating a global mechanical behaviour more close to that of an optimized characteristic closed-cell structure.

This model does not take directly into account the possible presence of secondary phases such as $\mathrm{GnP}$ and thus how different filler concentrations and final morphologies may affect the mechanical performance of foams. Therefore, in order to investigate the influence of the 
addition of GnP, $E_{\text {sp }}$ was calculated and presented for both Series 1 and Series 2 foams as a function of $\mathrm{GnP}$ concentration (Figure 6 (c)). A clearer effect of mechanical reinforcement (i.e., $E_{\text {sp }}$ enhancement) with increasing the amount of $\mathrm{GnP}$ can be seen for both series of foams. In this particular case, the foams of Series 2 did not seem to achieve an enhancement in their specific storage moduli when compared to that of Series 1 foams at equal GnP concentration, which, as mentioned before, can be either related to a reduction in the size of the nanoplatelets due to sonication and/or differences in cellular morphology.

\subsection{Electrical conductivity}

Ultrasonication has been proven useful in promoting the formation of an electricallyconductive network in polymer nanocomposites containing carbon-based nanoparticles at lower nanoparticle concentrations [8-10]. Therefore, as enhancement of the electrical conductivity was one of the main goals of this work, high power sonication was used prior to foaming in order to improve the dispersion and avoid re-agglomeration of GnP stacks.

As presented in Figure 7 (a), the electrical conductivity of the foams increased remarkably with incrementing GnP's concentration in both series of foams. Series 2 foams presented considerably higher electrical conductivities than Series 1 foams at equal GnP concentration, with this enhancement being more significant at higher $\mathrm{GnP}$ amounts. A remarkable increase of six orders of magnitude from $1.8 \times 10^{-7} \mathrm{~S} / \mathrm{m}$ to $1.7 \times 10^{-1} \mathrm{~S} / \mathrm{m}$ was observed when sonicating for foams containing the highest concentration of $\mathrm{GnP}(10 \mathrm{wt} \%)$, one of the highest values of electrical conductivity achieved so far for porous materials prepared using the WVIPS method.

Interestingly, as Series 2 foams displayed lower densities than Series 1 as a result of lower PEI concentration, the electrical conductivity of PEI-GnP foams could be raised with augmenting the porosity, i.e., with reducing density (see Figure 7 (a)). Hence, it was possible to obtain foams with higher electrical conductivities with apparently lower volume fractions of conductive GnP (see Figure 7 (b)). The key factor was the combination of enhanced GnP dispersion by means of sonication, as previously demonstrated by the decrease of the peak height corresponding to the (002) crystal plane of GnP (see values in Table 2), and reduction of the effective distance between conductive GnP stacks resulting from an increase in porosity, promoting the probability of electrical conduction by mechanisms such as tunneling $[17,18]$. 
Furthermore, with the objective of analyzing the influence of porosity independently from other factors, some foams from Series 2 having an equal composition ( 2 and $5 \mathrm{wt} \% \mathrm{GnP}$ ) and variable porosities were prepared and analyzed. Results, presented in Figure 7 (a), show that incrementing the porosity provokes an additional increase in electrical conductivity. Said results can be explained by the further reduction of $\mathrm{GnP}$ inter-particle distance as a consequence of a decrease in the characteristic dimension of the solid phase in the foams through a more favorable reorientation of GnP particles. A modeling study of percolation behaviour of foams with carbon-based nanofillers by O. Maxian et al. [19] showed that the percolation threshold tends to decrease with increasing the porosity due to the repositioning of the nanoparticles. Another work by G. Gedler et al. [20] showed that PC-based foams with $\mathrm{GnP}$ as conductive nanoparticles could reach electrical conductivity values up to $10^{-7} \mathrm{~S} / \mathrm{m}$ with increasing the expansion ratio. However, there seemed to be an optimum expansion ratio value above which there was a reduction in the efficiency of the electrical conduction mechanism.

In terms of electrical conduction models, percolative theory has been considered in numerous works dedicated to the study of the electrical conductivity of polymer nanocomposites containing carbon nanotubes [21-23] or graphene [24-27]. Percolative model assumes physical contact between the conductive particles and that the electrical conductivity $(\sigma)$ is proportional to the volume fraction of particles $(\phi)$ and the critical volume fraction of particles for electrical conduction $\left(\phi_{\mathrm{c}}\right)$, also known as percolation threshold, according to $\sigma \propto\left(\phi-\phi_{\mathrm{c}}\right)^{v}$, where $v$ is the percolation exponent $[2,27]$. Nevertheless, in this study, a tunnel conduction mechanism was proposed to be predominant in the experimental concentration range, as it has demonstrated to be a more feasible model to predict the electrical conductivity of thermoplastic polymer foams containing conductive carbon-based fillers, as explained in previous works of our research group [28]. The underlying justification of the application of this model is first of all related to the selected composition of the prepared samples (wide concentration range of particles) and secondly to the fact that the percolative model does not consider the possible existence of a semi-conductive behaviour for concentrations below the percolation threshold [28-30].

We have shown in one of our previous works [28] that the physical foaming of carbon nanofibre-reinforced polypropylene (PP-CNF) foams promoted the rupture of $\mathrm{CNF}$ aggregates, pushing them closer and effectively reducing the tunnel distance for electrical conduction, leading to a conductive network system of random-distributed conductive 
nanofibres. In the particular case of the WVIPS method used in this work to prepare the PEI$\mathrm{GnP}$ foams, sonication prior to foaming further enhanced the dispersion of GnP stacks, the average distance between stacks remaining proportional and more fitting to a $3 \mathrm{D}$ random particle distribution model (aggregates of GnP layers or GnP stacks) rather than a 2D network (distribution of fully exfoliated graphene layers). As demonstrated by the best fit of the electrical conductivity model, the mean distance between conductive particles seems to be proportional to $\phi^{-1 / 5}$ instead of $\phi^{-1 / 3}$ (see Figure $7(\mathrm{~b})$ ), where the exponents represent the geometry factors that define the previously mentioned morphology of the conductive particles $[31,32]$. These results prove that GnP stacks were not fully exfoliated and separated in individual graphene layers after sonication and foaming, hence the appearance of the characteristic (002) diffraction plane of graphite in the XRD spectra of PEI-GnP foams.

Although full exfoliation of GnP was not attained, the enhanced dispersion of GnP stacks by combining sonication and foaming was effective in the formation of a conductive network by lowering the average distance between conductive particles (GnP stacks) required for tunnel conduction, leading to low density foams with enhanced electrical conductivities.

\section{Conclusions}

Series 2 foams prepared with lower PEI concentration displayed a higher average cell size than foams from Series 1, direct consequence of their lower density. Sonication had a minor influence on the resultant average cell size, with only a slight cell size reduction being observed in Series 2 foams with increasing sonicated GnP concentration. No clear tendency was observed in terms the cell size of Series 1 foams with varying GnP concentration. Furthermore, sonication prior to foaming promoted a better dispersion of GnP stacks throughout PEI's matrix in foams from Series 2, as demonstrated by XRD spectra and SEM micrographs.

Regarding thermal stability, both series of foams displayed similar behaviour at the onset of thermal decomposition and a delay at advanced stages of decomposition with increasing the concentration of GnP up to $10 \mathrm{wt} \%$.

The stiffness of foams increased with increasing GnP concentration in both series. Particularly, Series 1 foams, with a higher PEI concentration in the initial solution, revealed greater values of modulus than Series 2 foams, direct result of their higher density and finer cellular structure. The possible rupture of $\mathrm{GnP}$ during high power sonication could have also had a role in reducing the modulus of foams from Series 2. 
Sonication led to foams with considerably higher electrical conductivities. Increases as high as six orders of magnitude were observed and assigned to an effective reduction of the distance between conductive GnP particles. Tunnel conduction assumption demonstrated the existence of a 3D random network in sonicated PEI-GnP foams as a consequence of improved dispersion of GnP. This finding would support that a full $\mathrm{GnP}$ exfoliation would not necessarily be required in order to achieve high electrical conductivities in this kind of foams.

\section{Acknowledgements}

The authors would like to acknowledge the Spanish Ministry of Economy and Competitiveness for the financial support of project MAT2014-56213. 


\section{References}

1. Abbasi, H., M. Antunes, and J.I. Velasco, Graphene nanoplatelets-reinforced polyetherimide foams prepared by water vapor-induced phase separation. Express Polymer Letters, 2015. 9(5): p. 412-423.

2. Ling, J., et al., Facile Preparation of Lightweight Microcellular Polyetherimide/Graphene Composite Foams for Electromagnetic Interference Shielding. ACS applied materials \& interfaces, 2013. 5(7): p. 2677-2684.

3. Shen, B., et al., Lightweight, Multifunctional Polyetherimide/Graphene@Fe3O4 Composite Foams for Shielding of Electromagnetic Pollution. ACS Applied Materials \& Interfaces, 2013. 5(21): p. 11383-11391.

4. Zhai, W., et al., Fabrication of lightweight, flexible polyetherimide/nickel composite foam with electromagnetic interference shielding effectiveness reaching $103 \mathrm{~dB}$. Journal of Cellular Plastics, 2014. 50(6): p. 537-550.

5. $\quad$ Li, J., et al., Cell morphology and mechanical properties of microcellular MuCell $\mathbb{}$ injection molded polyetherimide and polyetherimide/fillers composite foams. Journal of Applied Polymer Science, 2013. 130(6): p. 4171-4181.

6. Wu, H., B. Rook, and L.T. Drzal, Dispersion optimization of exfoliated graphene nanoplatelet in polyetherimide nanocomposites: Extrusion, precoating, and solid state ball milling. Polymer Composites, 2013. 34(3): p. 426-432.

7. Bonaccorso, F., et al., Production and processing of graphene and $2 d$ crystals. Materials Today, 2012. 15(12): p. 564-589.

8. Zhou, J., et al., Fabrication and mechanical properties of phenolic foam reinforced with graphene oxide. Polymer Composites, 2014. 35(3): p. 581-586.

9. Yang, H., et al., Covalent functionalization of chemically converted graphene sheets via silane and its reinforcement. Journal of Materials Chemistry, 2009. 19(26): p. $4632-4638$.

10. Chen, L., et al., A design of gradient interphase reinforced by silanized graphene oxide and its effect on carbon fiber/epoxy interface. Materials Chemistry and Physics, 2014. 145(1): p. 186-196.

11. Li, B., et al., Simultaneous enhancements in damping and static dissipation capability of polyetherimide composites with organosilane surface modified graphene nanoplatelets. Polymer, 2011. 52(24): p. 5606-5614.

12. $\mathrm{Wu}, \mathrm{H}$. and L.T. Drzal, Graphene nanoplatelet $\square$ polyetherimide composites: Revealed morphology and relation to properties. Journal of Applied Polymer Science, 2013. 130(6): p. 4081-4089.

13. Li, W., et al., A facile method to produce graphene oxide-g-poly (L-lactic acid) as an promising reinforcement for PLLA nanocomposites. Chemical Engineering Journal, 2014. 237: p. 291-299.

14. Sims, G.L.A. and C. Khunniteekool, CELL-SIZE MEASUREMENT OF POLYMERIC FOAMS. Cellular Polymers, 1994. 13(2): p. 137-146.

15. Realinho, V., et al., Thermal stability and fire behaviour of flame retardant high density rigid foams based on hydromagnesite-filled polypropylene composites. Composites Part B: Engineering, 2014. 58(0): p. 553-558.

16. Gibson, L.J. and M.F. Ashby, Cellular solids: structure and properties. 1999: Cambridge university press.

17. Ryvkina, N., et al., The deformation behavior of conductivity in composites where charge carrier transport is by tunneling: theoretical modeling and experimental results. Synthetic metals, 2005. 148(2): p. 141-146. 
18. Antunes, M., et al., Graphene Nanoplatelets as a Multifunctional Filler for Polymer Foams. Materials Today: Proceedings, 2016. 3: p. S233-S239.

19. O. Maxian, D.P., I. Manas-Zloczower, Conductive polymer foams with carbon nanofillers - Modeling percolation behavior. eXPRESS Polymer Letters, 2017. 11(5): p. 406-418.

20. Gedler, G., M. Antunes, and J.I. Velasco, Enhanced electrical conductivity in graphene-filled polycarbonate nanocomposites by microcellular foaming with scCO2. Journal of Adhesion Science and Technology, 2016. 30(9): p. 1017-1029.

21. Hou, S., et al., Formation of highly stable dispersions of silane-functionalized reduced graphene oxide. Chemical Physics Letters, 2010. 501(1): p. 68-74.

22. Lin, Y., J. Jin, and M. Song, Preparation and characterisation of covalent polymer functionalized graphene oxide. Journal of Materials Chemistry, 2011. 21(10): p. 34553461.

23. Fang, M., et al., Covalent polymer functionalization of graphene nanosheets and mechanical properties of composites. Journal of Materials Chemistry, 2009. 19(38): p. 7098-7105.

24. Boukhvalov, D. and M. Katsnelson, Chemical functionalization of graphene with defects. Nano letters, 2008. 8(12): p. 4373-4379.

25. Gao, X., J. Jang, and S. Nagase, Hydrazine and thermal reduction of graphene oxide: reaction mechanisms, product structures, and reaction design. The Journal of Physical Chemistry C, 2009. 114(2): p. 832-842.

26. Iqbal, M.Z., et al., Effect of solvent on the uncatalyzed synthesis of aminosilanefunctionalized graphene. RSC Advances, 2014. 4(13): p. 6830-6839.

27. Stankovich, S., et al., Graphene-based composite materials. Nature, 2006. 442(7100): p. 282-286.

28. Antunes, M., M. Mudarra, and J.I. Velasco, Broad-band electrical conductivity of carbon nanofibre-reinforced polypropylene foams. Carbon, 2011. 49(2): p. 708-717.

29. Barrau, S., et al., DC and AC conductivity of carbon nanotubes-polyepoxy composites. Macromolecules, 2003. 36(14): p. 5187-5194.

30. Linares, A., et al., Broad-band electrical conductivity of high density polyethylene nanocomposites with carbon nanoadditives: multiwall carbon nanotubes and carbon nanofibers. Macromolecules, 2008. 41(19): p. 7090-7097.

31. Mann, J.A. and W.R. Dichtel, Noncovalent functionalization of graphene by molecular and polymeric adsorbates. The Journal of Physical Chemistry Letters, 2013. 4(16): p. 2649-2657.

32. Mann, J.A., et al., Multivalent binding motifs for the noncovalent functionalization of graphene. Journal of the American Chemical Society, 2011. 133(44): p. 17614-17617. 


\section{Figure captions}

Figure 1. SEM micrographs showing the general view of Series 2 PEI-GnP foams containing (a) $1 \mathrm{wt} \%$, (b) $2 \mathrm{wt} \%$, (c) $5 \mathrm{wt} \%$ and (d) $10 \mathrm{wt} \% \mathrm{GnP}$.

Figure 2. Comparison between (a) Series 1 and (b) Series 2 PEI-GnP foams with $10 \mathrm{wt} \%$ $\mathrm{GnP}$, respectively showing (a) GnP mostly confined in the cell struts with only few platelets in the cell walls and (b) improved GnP dispersion in both struts and cell walls.

Figure 3. XRD spectra of Series 1 (high density) and Series 2 (low density) PEI-GnP foams showing reduction of GnP's (002) diffraction plane with increasing porosity.

Figure 4. TGA and dTG thermograms of PEI foam and Series 2 PEI-GnP foams.

Figure 5. Comparative evolution of the decomposition temperatures of PEI-GnP foams (Series 1: filled symbols; Series 2: hollow symbols).

Figure 6. (a) Typical storage modulus, loss modulus and tan $\delta$ curves of PEI-GnP foam with $1 \mathrm{wt} \%$ of $\mathrm{GnP}$ (Series 2 ) and (b) normalized storage modulus $\left(E^{\prime}{ }_{\text {norm }}\right)$ at $30^{\circ} \mathrm{C}$ versus relative density and (c) specific storage modulus $\left(E^{\prime}{ }_{\mathrm{sp}}\right)$ at $30{ }^{\circ} \mathrm{C}$ versus $\mathrm{GnP}$ concentration for Series 1 and Series 2 PEI-GnP foams.

Figure 7. (a) Evolution of the electrical conductivity with porosity for Series 1 and Series 2 PEI-GnP foams and (b) representation of the fitting results of the electrical conductivity versus $\phi^{-1 / 5}$, demonstrating tunnel conduction characteristic of a $3 \mathrm{D}$ random particle distribution system formed by conductive GnP stacks. 

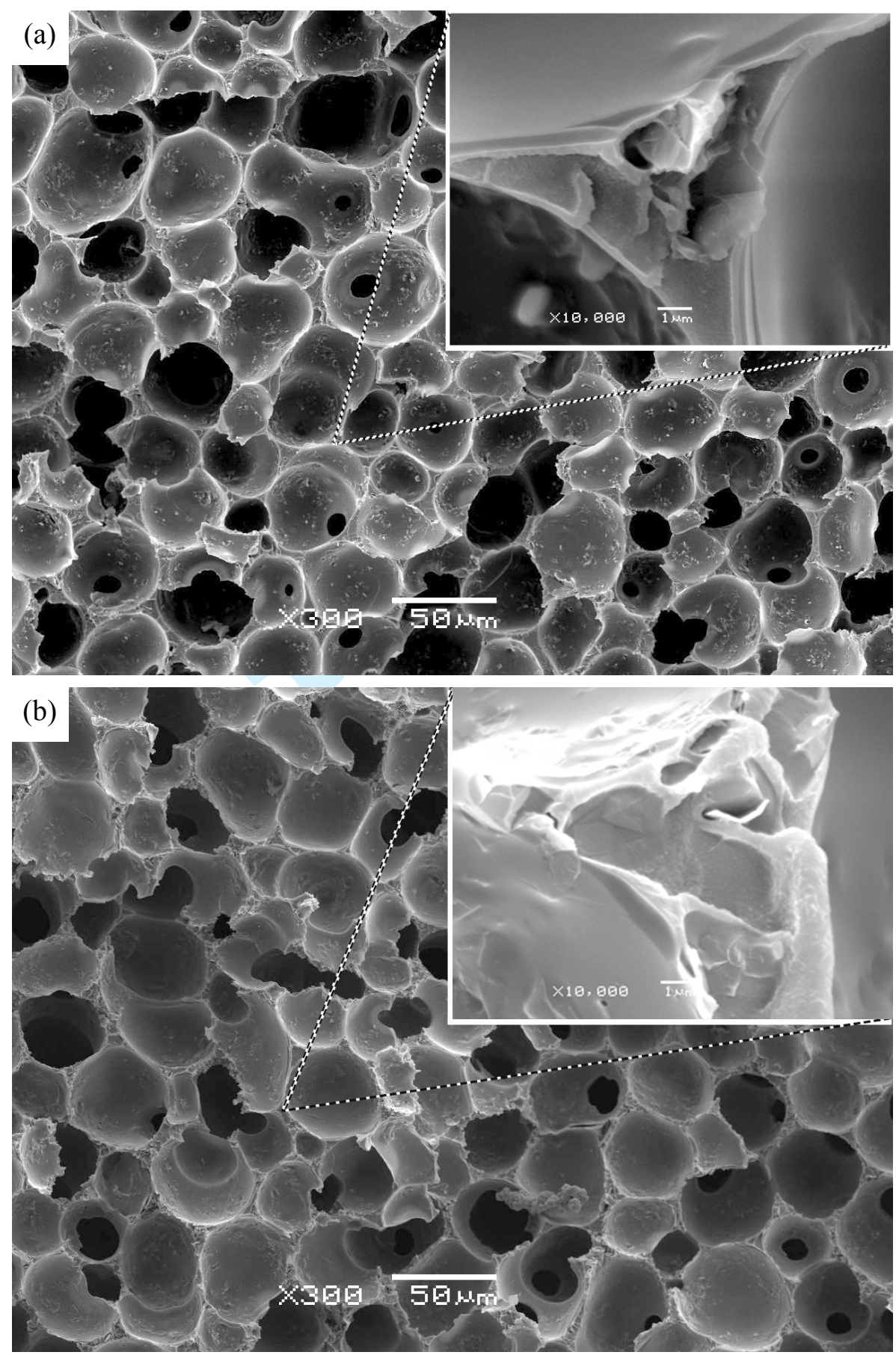

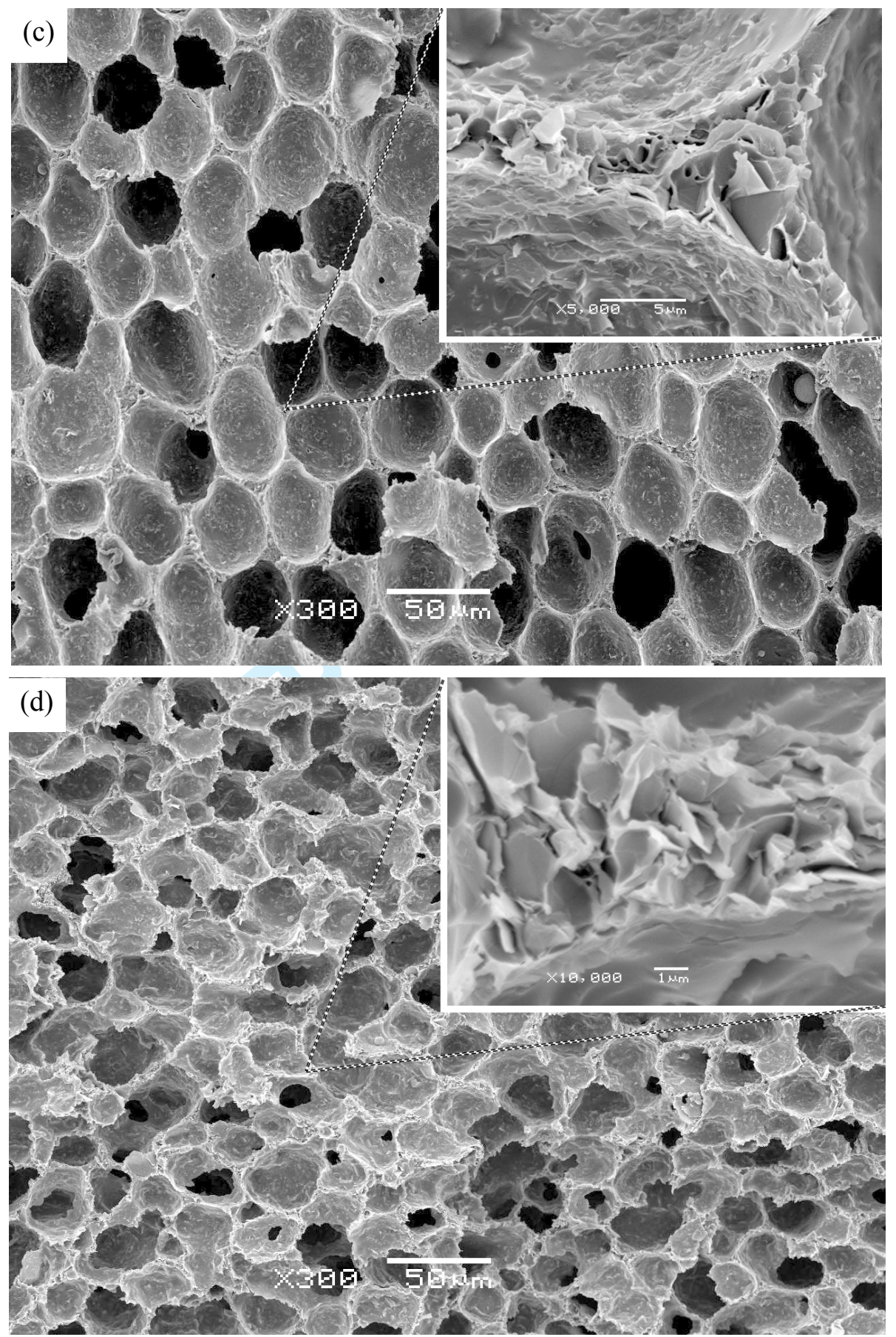

Figure 1. SEM micrographs showing the general view of Series 2 PEI-GnP foams containing (a) $1 \mathrm{wt} \%$, (b) $2 \mathrm{wt} \%$, (c) $5 \mathrm{wt} \%$ and (d) $10 \mathrm{wt} \% \mathrm{GnP}$. 


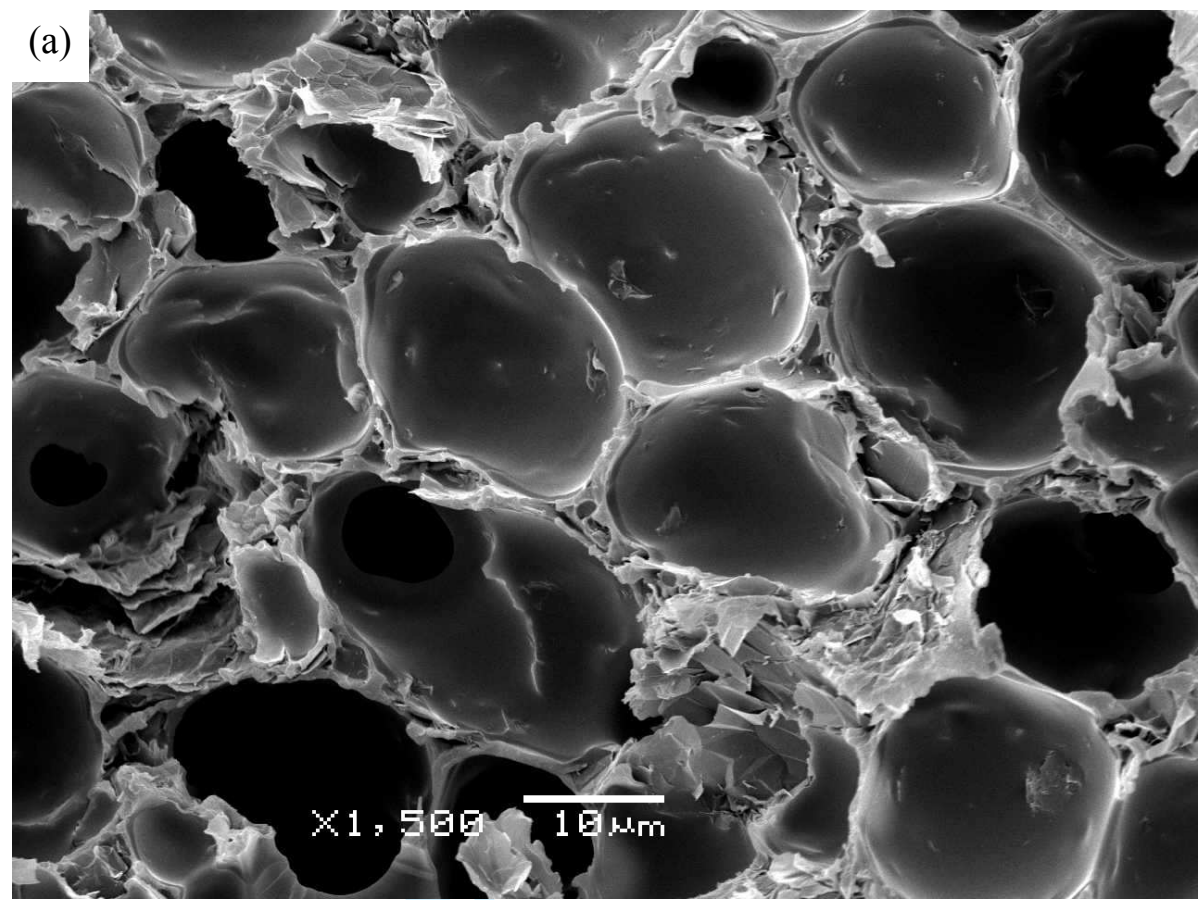

(b)

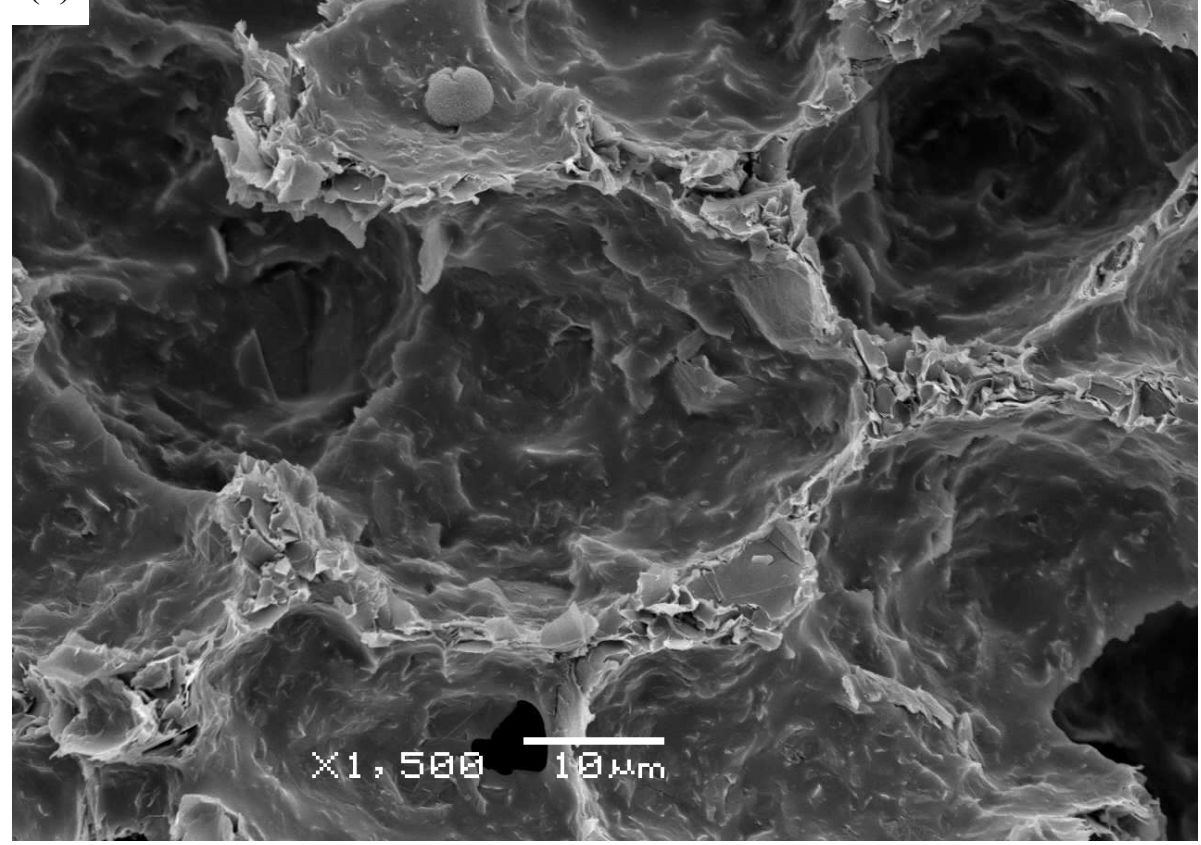

Figure 2. Comparison between (a) Series 1 and (b) Series 2 PEI-GnP foams with 10 $\mathrm{wt} \% \mathrm{GnP}$, respectively showing (a) GnP mostly confined in the cell struts with only few platelets in the cell walls and (b) improved $\mathrm{GnP}$ dispersion in both struts and cell walls. 


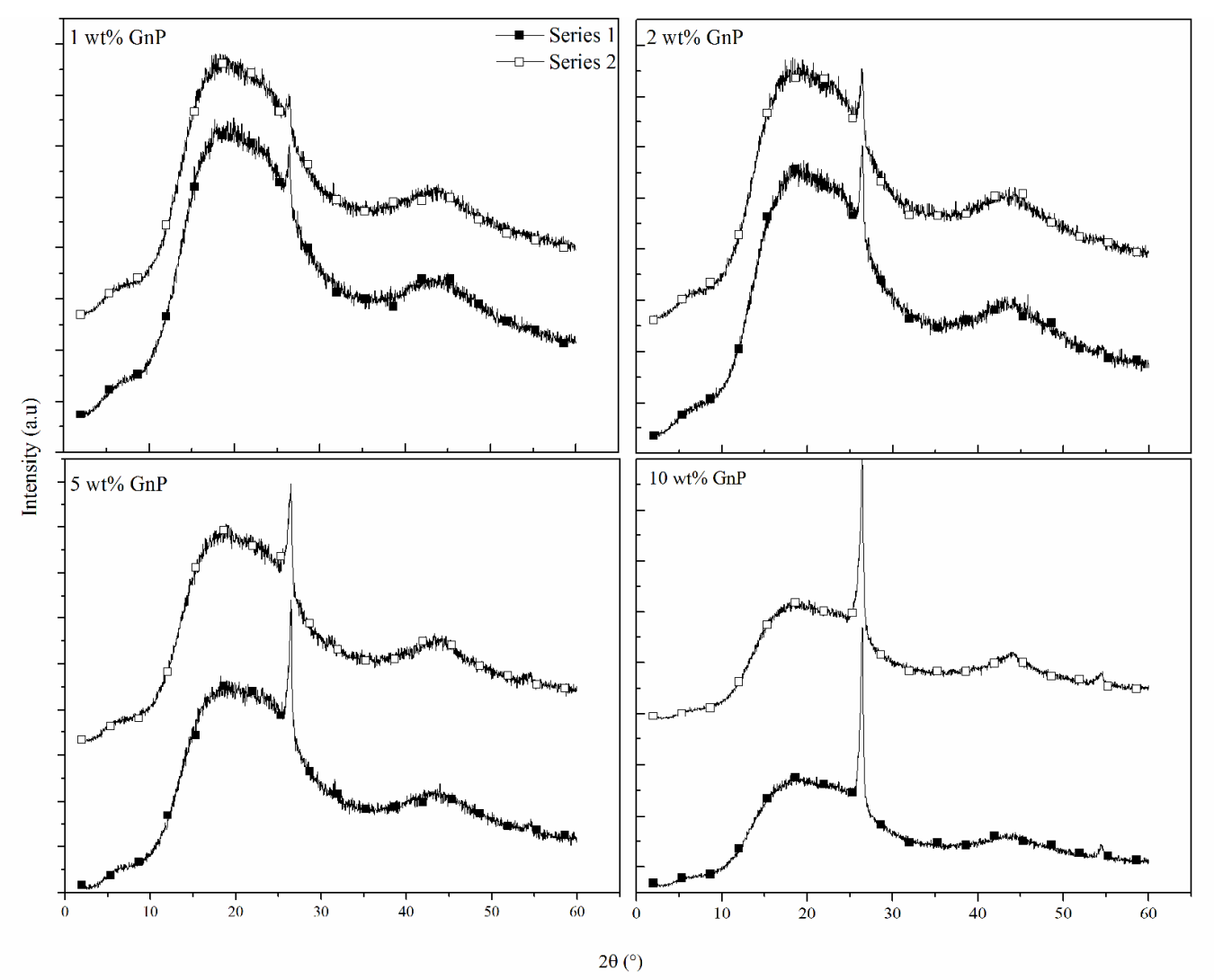

Figure 3. XRD spectra of Series 1 (high density) and Series 2 (low density) PEI-GnP foams showing reduction of GnP's (002) diffraction plane with increasing porosity. 


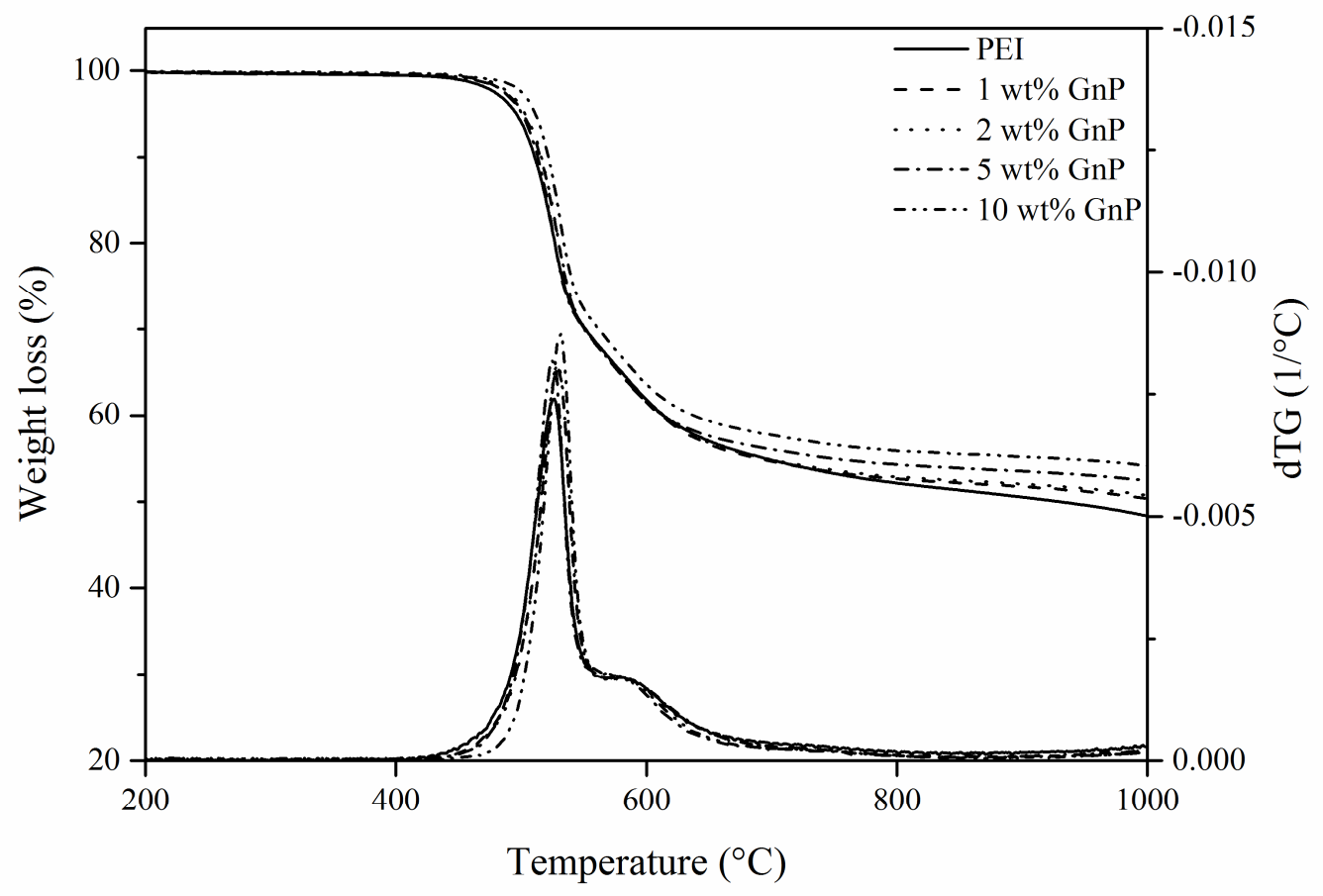

Figure 4. TGA and dTG thermograms of PEI foam and Series 2 PEI-GnP foams. 
Figure 5. Comparative evolution of the decomposition temperatures of PEI-GnP foams

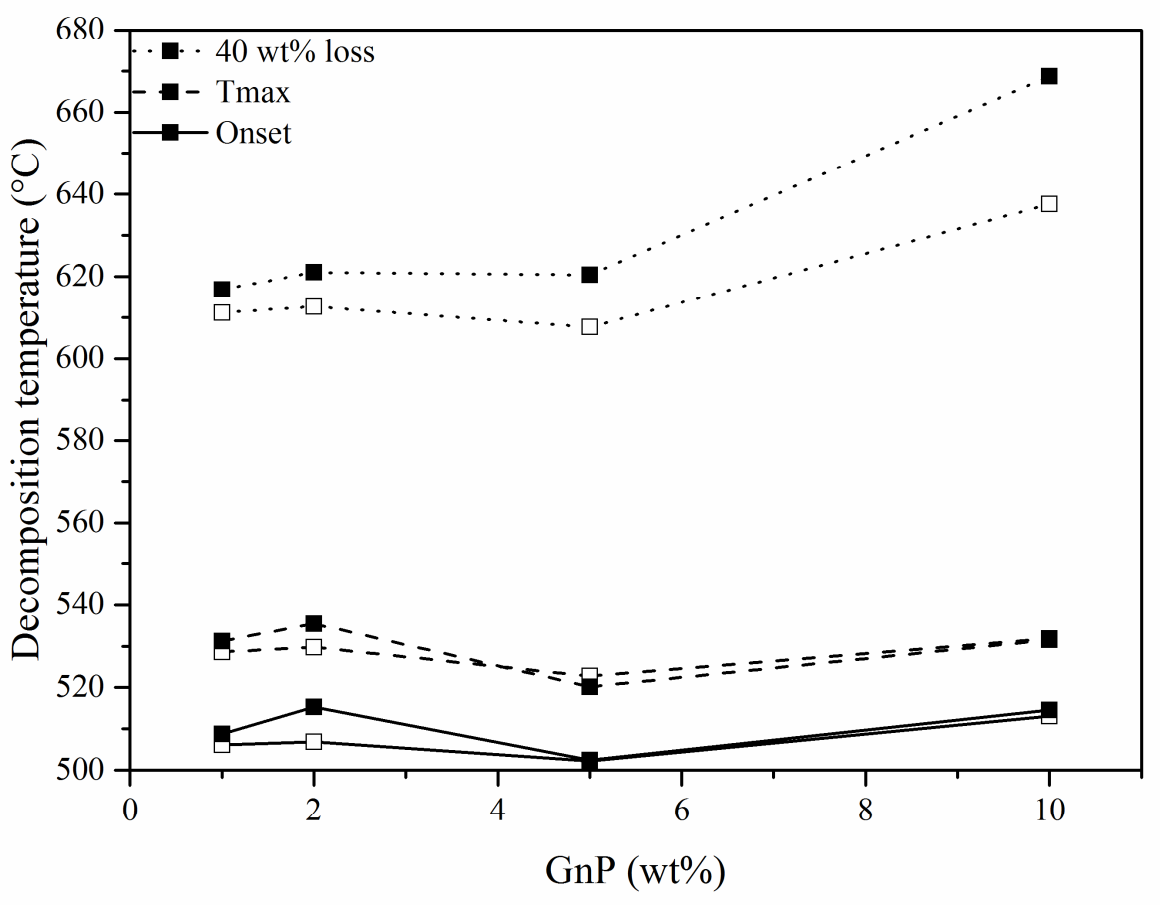

\section{(Series 1: filled symbols; Series 2: hollow symbols).}


(a)

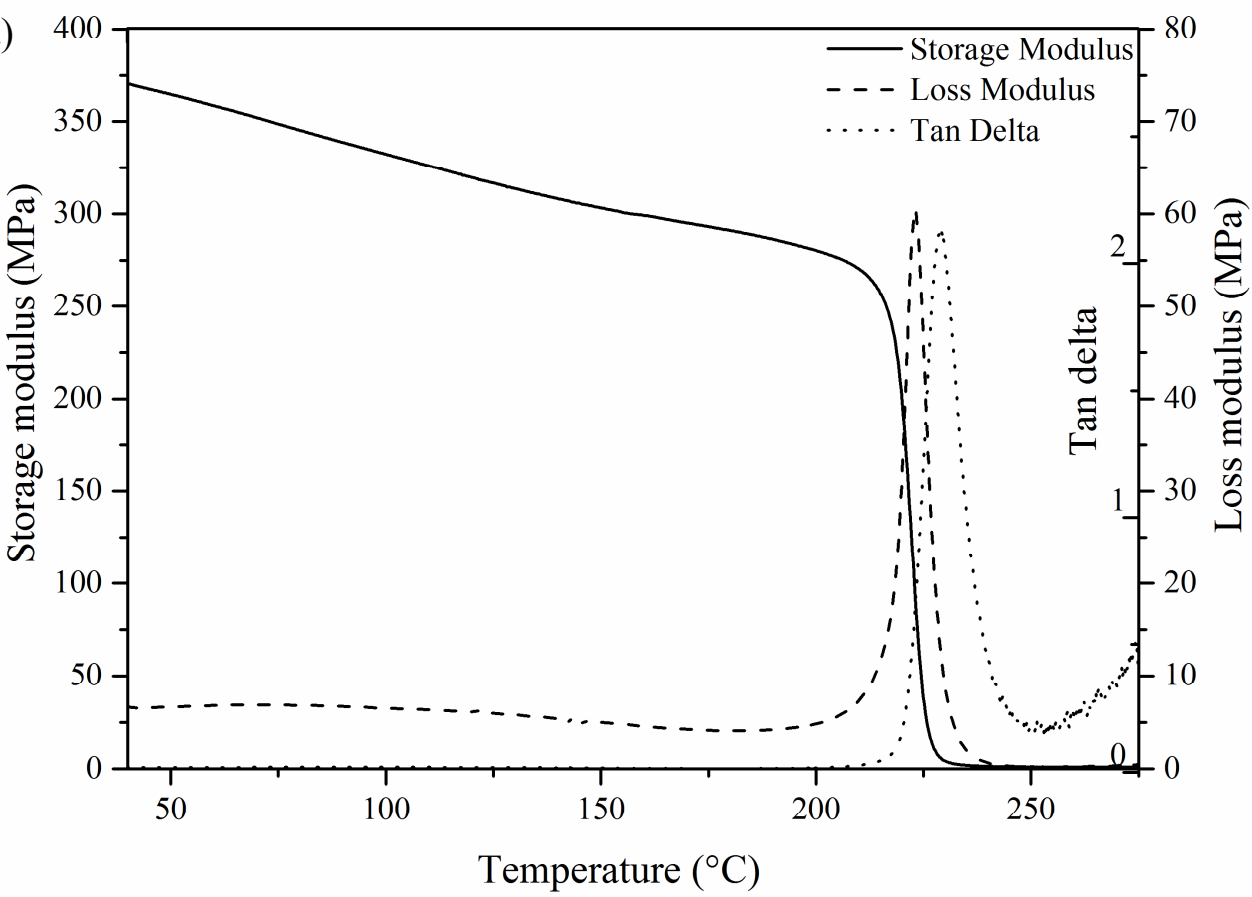

(b)

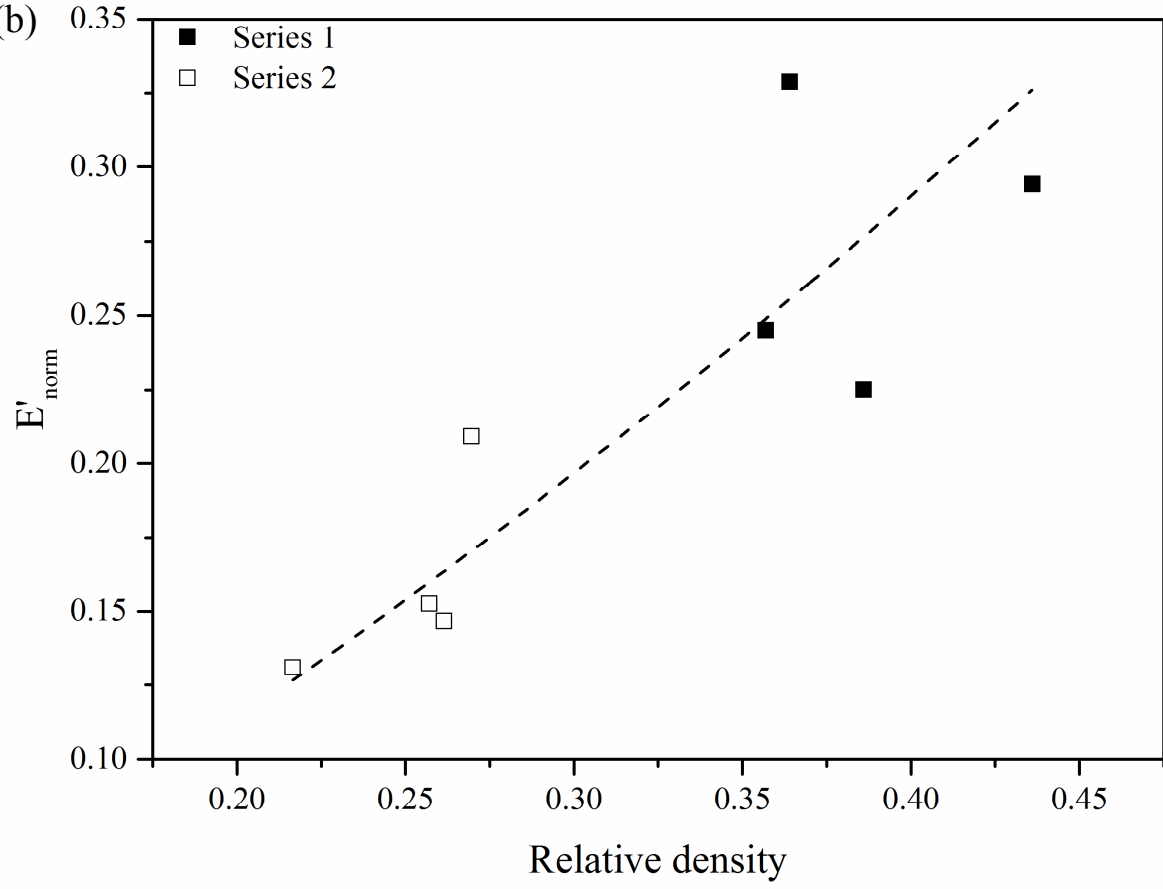


Figure 6. (a) Typical storage modulus, loss modulus and tan $\delta$ curves of PEI-GnP foam with $1 \mathrm{wt} \%$ of $\mathrm{GnP}$ (Series 2) and (b) normalized storage modulus ( $\left.E^{\prime}{ }_{\text {norm }}\right)$ at $30{ }^{\circ} \mathrm{C}$ versus relative density and (c) specific storage modulus $\left(E_{\text {sp }}\right)$ at $30{ }^{\circ} \mathrm{C}$ versus $\mathrm{GnP}$ concentration for Series 1 and Series 2 PEI-GnP foams. 


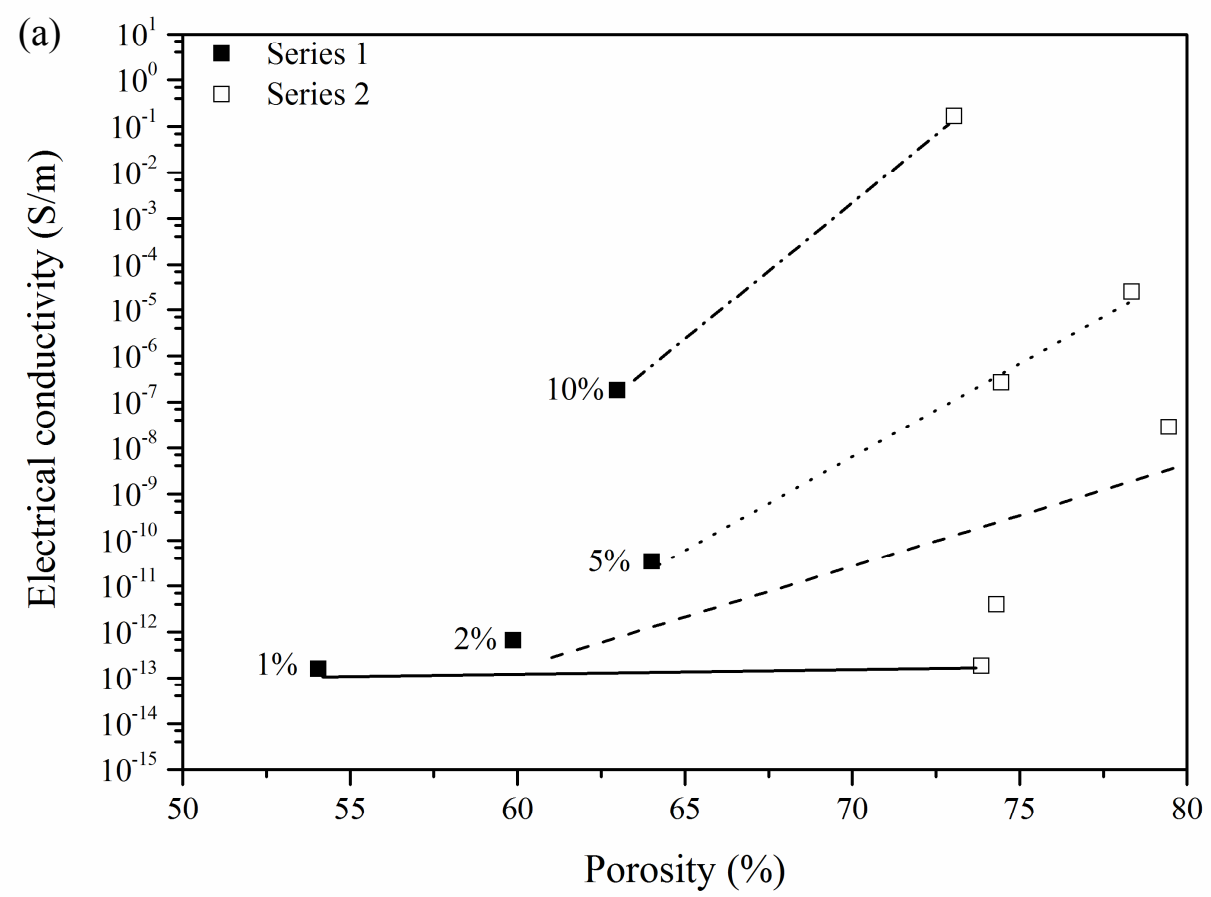

(b)

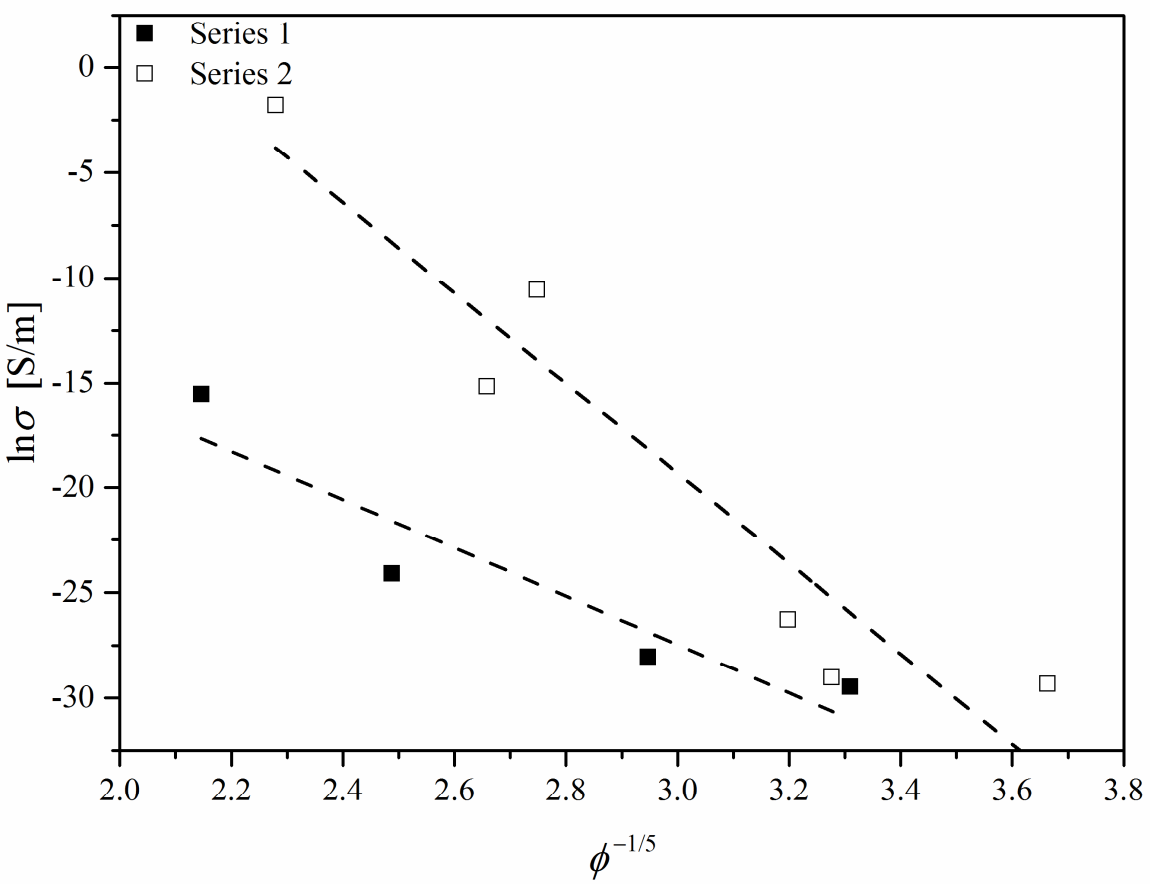

Figure 7. (a) Evolution of the electrical conductivity with porosity for Series 1 and Series 2 PEI-GnP foams and (b) representation of the fitting results of the electrical conductivity versus $\phi^{-1 / 5}$, demonstrating tunnel conduction characteristic of a 3D random particle distribution system formed by conductive GnP stacks. 
Table 1. Cellular structure characteristics of PEI-GnP foams.

\begin{tabular}{|c|c|c|c|c|c|}
\hline $\begin{array}{c}\text { GnP } \\
(\mathrm{wt} \%)\end{array}$ & $\begin{array}{c}\text { Density } \\
\left(\mathrm{g} / \mathrm{cm}^{3}\right)\end{array}$ & $\begin{array}{c}\text { Porosity } \\
(\%)\end{array}$ & $\begin{array}{c}\text { Cell size, } \Phi \\
(\mu \mathrm{m})\end{array}$ & $\begin{array}{c}\text { Cell density, } \\
N_{\mathrm{f}}\left(\mathrm{cells} / \mathrm{cm}^{3}\right)\end{array}$ & $\begin{array}{c}\text { Cell density, } \\
N_{0}\left(\mathrm{cells} / \mathrm{cm}^{3}\right)\end{array}$ \\
\hline \multicolumn{7}{|c|}{ Series 1} \\
\hline 1.0 & 0.586 & 54.1 & $11.3 \pm 3.5$ & $1.3 \times 10^{9}$ & $2.2 \times 10^{9}$ \\
\hline 2.0 & 0.514 & 59.9 & $11.5 \pm 3.7$ & $1.4 \times 10^{9}$ & $3.4 \times 10^{9}$ \\
\hline 5.0 & 0.467 & 64.0 & $13.6 \pm 5.0$ & $1.1 \times 10^{9}$ & $2.2 \times 10^{9}$ \\
\hline 10.0 & 0.491 & 63.0 & $13.5 \pm 5.2$ & $6.9 \times 10^{8}$ & $2.2 \times 10^{9}$ \\
\hline & & & Series 2 & & $1.0 \times 10^{8}$ \\
\hline 1.0 & 0.333 & 73.9 & $37.0 \pm 10.7$ & $2.8 \times 10^{7}$ & $1.2 \times 10^{8}$ \\
\hline 2.0 & 0.329 & 74.3 & $33.2 \pm 10.4$ & $3.9 \times 10^{7}$ & $1.5 \times 10^{8}$ \\
\hline 5.0 & 0.281 & 78.3 & $31.8 \pm 9.1$ & $4.7 \times 10^{7}$ & $3.2 \times 10^{8}$ \\
\hline 10.0 & 0.357 & 73.0 & $23.3 \pm 8.5$ & $1.1 \times 10^{8}$ & \\
\hline
\end{tabular}


Table 2. Intensity and FWHM of GnP's (002) diffraction plane for PEI-GnP foams.

\begin{tabular}{|c|c|c|c|c|}
\hline $\begin{array}{c}\text { GnP } \\
(\mathrm{wt} \%)\end{array}$ & $\begin{array}{c}\text { Density } \\
\left(\mathrm{g} / \mathrm{cm}^{3}\right)\end{array}$ & $\begin{array}{c}\text { Porosity } \\
(\%)\end{array}$ & $\begin{array}{c}\text { Intensity } \\
(\mathrm{a} . \mathrm{u} .)\end{array}$ & $\begin{array}{c}\text { FWHM } \\
\left({ }^{\circ}\right)\end{array}$ \\
\hline \multicolumn{5}{|c|}{ Series 1} \\
\hline 1.0 & 0.586 & 54.1 & 602.3 & 0.34 \\
\hline 2.0 & 0.514 & 59.9 & 739.8 & 0.41 \\
\hline 5.0 & 0.467 & 64.0 & 1480.1 & 0.32 \\
\hline 10.0 & 0.491 & 63.0 & 3382.1 & 0.37 \\
\hline \multicolumn{5}{|c|}{ Series 2} \\
\hline 1.0 & 0.333 & 73.9 & 354.2 & 0.56 \\
\hline 2.0 & 0.329 & 74.3 & 601.5 & 0.41 \\
\hline 5.0 & 0.281 & 78.3 & 1060.3 & 0.42 \\
\hline 10.0 & 0.357 & 73.0 & 3259.3 & \\
\hline
\end{tabular}


Table 3. Thermogravimetric results of PEI-GnP foams.

\begin{tabular}{|c|c|c|c|c|c|c|}
\hline \multirow{2}{*}{$\begin{array}{l}\mathrm{GnP} \\
(\mathrm{wt} \%)\end{array}$} & \multirow{2}{*}{$\begin{array}{l}\text { Density } \\
\left(\mathrm{g} / \mathrm{cm}^{3}\right)\end{array}$} & \multirow{2}{*}{$\begin{array}{c}\text { Porosity } \\
\text { (\%) }\end{array}$} & \multicolumn{3}{|c|}{ Decomposition temperature $\left({ }^{\circ} \mathrm{C}\right)$} & \multirow{2}{*}{$\begin{array}{l}\text { Residue at } 1000 \\
{ }^{\circ} \mathrm{C}(\mathrm{wt} \%)\end{array}$} \\
\hline & & & Onset & $T_{\max }$ & $\begin{array}{c}40 \mathrm{wt} \% \\
\text { loss }\end{array}$ & \\
\hline \multicolumn{7}{|c|}{ Series 1} \\
\hline 1.0 & 0.586 & 54.1 & 508.8 & 531.3 & 616.9 & 52.0 \\
\hline 2.0 & 0.514 & 59.9 & 515.3 & 535.5 & 621.9 & 51.7 \\
\hline 5.0 & 0.467 & 64.0 & 502.5 & 520.2 & 614.3 & 52.7 \\
\hline 10.0 & 0.491 & 63.0 & 514.5 & 531.6 & 668.8 & 55.8 \\
\hline \multicolumn{7}{|c|}{ Series 2} \\
\hline 1.0 & 0.333 & 73.9 & 506.1 & 528.6 & 611.2 & 50.4 \\
\hline 2.0 & 0.329 & 74.3 & 506.9 & 529.8 & 612.6 & 50.8 \\
\hline 5.0 & 0.281 & 78.3 & 502.3 & 522.8 & 607.8 & 51.7 \\
\hline 10.0 & 0.357 & 73.0 & 513.8 & 531.9 & 637.6 & 54.1 \\
\hline
\end{tabular}


Table 4. Foam's storage modulus and glass transition temperature obtained from the maximum of the transition peak in both loss modulus (E") and tan $\delta$ curves for PEIGnP foams.

\begin{tabular}{|c|c|c|c|c|c|}
\hline $\begin{array}{c}\mathrm{GnP} \\
(\mathrm{wt} \%)\end{array}$ & $\begin{array}{l}\text { Density } \\
\left(\mathrm{g} / \mathrm{cm}^{3}\right)\end{array}$ & $\begin{array}{c}\text { Porosity } \\
(\%)\end{array}$ & $\begin{array}{c}E \\
(\mathrm{MPa})\end{array}$ & $\begin{array}{c}\mathrm{T}_{E}{ }^{\prime} \text { max } \\
\left({ }^{\circ} \mathrm{C}\right)\end{array}$ & $\begin{array}{c}\mathrm{T}_{\tan \delta \max } \\
\left({ }^{\circ} \mathrm{C}\right)\end{array}$ \\
\hline \multicolumn{6}{|c|}{ Series 1} \\
\hline 1.0 & 0.586 & 54.1 & 1335.6 & 218.0 & 225.0 \\
\hline 2.0 & 0.514 & 59.9 & 1147.7 & 219.4 & 226.7 \\
\hline 5.0 & 0.467 & 64.0 & 1334.7 & 216.0 & 222.9 \\
\hline 10.0 & 0.491 & 63.0 & 1718.2 & 215.4 & 221.4 \\
\hline \multicolumn{6}{|c|}{ Series 2} \\
\hline 1.0 & 0.333 & 73.9 & 370.4 & 223.1 & 229.0 \\
\hline 2.0 & 0.329 & 74.3 & 385.3 & 223.3 & 228.6 \\
\hline 5.0 & 0.281 & 78.3 & 330.8 & 216.3 & 224.0 \\
\hline 10.0 & 0.357 & 73.0 & 527.8 & 223.2 & 229.4 \\
\hline
\end{tabular}

